supernatural causes. In this way when $\mathrm{Ch}^{\prime}$ 'ên Kwah met in the course of his investigations with flint and bronze implements he at once adopted the common opinion of his countrymen, which is the same as that which was prevalent in Europe a couple of centuries ago, that they were thunderbolts shot down by the God of Thunder in the explosions of his wrath. In confirmation of this theory Ch'ên states that though these implements are found all over the country they are more plentiful in districts, such as Lui-chow in the province of Canton, where thunderstorms are more than usually prevalent. In shape, he tells us, they resemble axes, knives, small hammers several pounds in weight, skewers or nails, and other pointed implements. In colour they vary, some being yellow, some green, and some black. Some of the axesbaped stones are bored with two boles, but the majority are not pierced, and implements of the same shape are found in bronze and irorr.

Speaking within his own knowledge he only describes the circumstances of the discovery of two stone axes, both of which he tells us were found beneath trees. In one case, at Sin-chow, in Hupeh, after a severe thunderstorm in which, like Prospero, the God of Thunder had

$$
\text { "With his own bolt," }
$$

a stone axe was found at its roots; and on another occasion at Sui-chow, under precisely similar circumstances, a shepherd-lad found a "fire stone in the shape of an axe." As in the only two cases about which Ch'ên speaks from personal knowledge the axes were found beneath trees, it is not unnatural to suppose that they are more frequently found in that position than elsewhere; and this becomes interesting when we find it stated by Mr. Rivett Carnac in a valuable paper published in vol. lii. of the Procectings of the Bengal Branch of the Royal Asiatic Society, that it is the custom in Central India for the finder of a stone axe or other stone implement to place it "under the village pipul tree," and sometimes to sanctify it with a daub of red paint, and thus to constitute it a Mahadeo. A somewhat similar practice exists, according to Chinese historians, in a country vaguely described as being to the west of the Yub Pass in Chinese Turkestan, where "thunder stones" when found are deposited in the temples. May not this Indian practice have also been the custom of some of the aboriginal tribes of China? and may not the fact that in the two instances mentioned above the axes were found at the roots of riven trees be evidence of the antiquity of the custom, as in cases described by Mr. Rivett Carnac, in which the roots of the trees and the surrounding soil had in course of years so completely grown over the axes that they could only be cut and dug out with difficulcy?

Stone arrow-heads do not seem to have come within Ch'èn's range of observation, although from historical references we know that they are to be met with in China. In the "Book of History," which is said to have been compiled by Confucius, mention is made of tribute, consisting of iron, silver, steel, and stone arrow heads, having been presented to the Chinese Court by the tribes on the Yellow River about the year 2200 13.C. The story is told also that on one occasion, as the Prince of Ch'ên (495 B.C.) was walking in the palace grounds, a bird fell dead at his feet, pierced through by a stone-headed arrow. As the kind of bird was unknown to the prince and his courtiers, Confucius was called in to give his opinion upon it. The bird he pronounced to be a species of sparrow-hawk from Northern Tartary, and he explained $t$ at the stone head which pointed the dart was similar to that which $\mathrm{Wu}$ Wang (B.C. II22) presented to his prince. It appears als, that stone arrow-heads were used in incient times as emblems of authority, and that they have very commonly been presented to sovereigns as objects of curiosity and value.
The biographical dictionaries tell us that in course of his official duties Ch'ên was called upon to direct extensive irrigating works; and no doubt the excavations and cuttings which he then superintended led him to take an interest in the fossil remains with which the country abounds. On this subject he has many notes. In one he tells us that at a certain spot on the Yellow River, the banks having fallen away for a considerable distance, a fossil bamboo grove was disclosed, a fact which excited his surprise, as the district is not one in which bamboos grow at the present day, and he contrasts with this the fossil peach-stones, roots of rushes, snakes and crabs, which are found at the Kin-hwa Mountain, all of which things are still indigenous in the neighbourhood. At Tsêh-chow in Shansi, he states, a man, when digging a well, suddenly unearthed a "lizard resembling a dragon." At sight of the monster the man fled in terror, but observing from a distance that it remained motionless, he ventured to return, when, to his relief, he found that it was petrified. Philistine-like, his neighbours broke it to pieces, and only one bit of it was preserved. Another kind of fossil has long been a puzzle to the philosophers, from the great and wise emperor, K'ang-hi (I66I-I720), downwards. Adventurous travellers who have braved the northern frosts have from time to time brought back accounts of the mammoths which are found in the frozen cliffs of Siberia. Deceived by a mistaken analogy, the Chinese wiseacres have arrived at the conclusion that these monsters must be huge ivory-producing rats, and, misinterpreting their continued preservation, have formed the opinion that darkness is necessary to their life, and that exposure to the outer air produces instant death. Their ivory is considered to be softer than elephant ivory, and in the hands of skilful chemists their flesh is said to make up into a highly invigorating tonic.

Speaking of the neighbourhood of the Loh River, Ch'ên mentions the discovery of ancient Troglodyte dwellings in which were found coins, and in one case a stone chest bearing on the outside fine tracings of flowers, birds, and other objects. Un the lid were inscribed upwards of twenty characters, which were of such an archaic form that they were undecipherable. But the contents were ea sily understood, and were at once recognised as pieces of pure gold.

Constant mention is made by Ch'ên of meteoric stones, which in popular imagination are said to assume various strange and uncanny forms. Of the desceni of one such stone which fell in the province of Kiang-su in the year 1064, he gives certain particulars on the authority of a Mrs. Heu. This lady, when in her garden one day, was startle 1 by an explosion like a peal of thunder, and saw a large "star nearly as big as the moon" pass across the sky from south-east to south-west, and eventually fall within a few yards of the place where she was standing. On going to the spot she observed a deep hole, at the bottom of which was the "star shining brightly." By degrees the light died away, and eventually at a depth of three feet she dug up a round stone of the size of a man's fist, and of the weight and appearance of iron. Altogether Ch'ên's work is well worthy of the study of those who can read Chinese and who are interested in the palæontology of China.

ROBERT K. DOUGLAS

\section{ON THE FORMATION OF STARCH IN LEAVES}

$\mathrm{N}$ a recent communication to the Arbeiten des botanisches Institut in Würzburg (Bd. iii.), Prof. Sachs gives the results of his work during the past summer in connection with the above subject. The investigations were made with the object of determining the formation and disappearance of starch in the leaves of plants growing in the open, and under normal conditions of vegeta- 
tion, and were carried on chiefly during the months of June, July, and August on a large number of Dicotyledons from various families. Some twenty-two years ago Prof. Sachs showed that the presence of starch in chlorophyll grains can readily be dete:ted by means of the now well-known iodine test, a modification of which was employed in these researches.

If fresh green leaves are plunged into boiling water for ten minutes or so, certain soluble substances are extracted, but the starch and colouring matter of the chlorophyl grains remain in the still unbroken cells of the mesophyll. A short immersion in alcohol now removes the green colouring-matter and certain bodies soluble in alcobol, leaving the starch behind in the colourless tissue. The presence of acids affe ts the decree of whiteness of the decolorised leaf; and the decolorisation proceed; more rapidly in sunlight or warm alcohol than in the dark and cold. Leaves of Tropaolum may be rendered completely white, like writing paper, in two or three minutes.

If the decolorised leaf be now placed in a strong solu tion of iodine in alcohol, the presence or absence of starch may be demonstrated in a few minutes. If no starch is present, the cellular tissue simply presents the well-known yellow colour; if a large quantity of starch exist; in the cells, the tissue appears blue-black, the venation appearing as a pale network in the dark ground. Paler colours result if but little starch is present at the time of the experiment.

It will readily be seen how useful the above method is for the purpose of demonstrating the absence of starch from etiolated leaves, the white vortions of variegated foliage, \&c, and the sequel shows that the method affords means of obtaining far more delicate results, without the trouble of a microscopic examination.

In the first place, the same leaf may be found to contain very different quantities of starch at different periods of the day, or according to the weather; and secondly, the increase and decrease of the quantities of starch in a given leaf may be very rapid.

Sachs showed long ago that if a plant is placed in the dark, the starch disappears from the leaves; and it has also been known for some time that if a piece of tinfoil is placed on a leaf, the covered portion forms no starch, although the parts exposed to light may become filled with that substance. Moreover, Kraus showed how very rapidly starch can be formed in direct sunlight.

Sachs now demonstrates on a number of plants that the starch formed in the leaves during the day may disappear completely during the night, and that the leaves shown to be full of starch in the evening may be quite empty of starch next morning. This depends upon the temperature and health of the plant, but ozcurs normally during the summer in plants growing in the open. $A$ large number of experiments are given in support of this, and showing how the rapidity and completion of the process depends upon the weather.

The experimental proof is very simple. A leaf is halved longitudinally at night, after a fine sunny day, and the excised half is shown to be filled with starch by the iodine test described; the remaining hilf is tested early next morning, and shows at once if any material diminution has occurred during the night. A simple and obvious modification of this experiment gives an idea of the quantity of starch formed between sunrise and sunset. The half leaf tested before sunrise shows no trace of starch : the other balf, left on the plant during the day, is found to become more and more filled with starch towards the afternoon.

Some curious results were arrived at as to the effect of growing parts on the rapidity of the emptying of the leaves; some of these matters still require investigation.

Differences in the weight of leaves and in the intersity of the colour produced by the iodine test, as well as some other observations, lead to a better understanding of a fact already known generally, viz. that the starch disappears from the leaves in the form of glucoses, which travel by way of the vascular bundles into the stems, and thus pass to the places where they are used up in growth.

Some very telling observations were made in this connection, and the dependence of the processes on temperature again show forth clearly.

These results lead to the conclusion that the process of metamorphosis into glucoses and translocation of the products of assimilation are also going on during daylight, though they are less evident, because more starch is then being formed and accumulated than is abstracted at the time. Moll proved that such is the case by exposing leaves to the sunlight, but in an atmosphere devoid of carbon dioxide ; the starch already in the leaves disappeared, and no more was formed to replace it. 'Sachs repe ited Moll's experiments, and proved the correctness of his conclusions by means of the iodine test. Half leaves were shown to be full of starch; the companion halves were put into closed atmospheres, deprived of carbon dioxide by means of potassium hydrate, and exposed to sunlight. In an hour the latter halves were tested, and found to be nearly emptied of starch. Other experiments proved that depletion occurred in a few hours, the time depending on the temperature.

Further experiments demonstrate that the starch travels in the form of glucoses in all the above cases; but it is not proved whether the metamorphosis is effected by forces in the chlorophyll grains themselves, or by means of diast atic ferments in the cells of the leaf. $\dot{A}$ few hints are here given showing a field for further research.

Perhaps the most ingenious part of the paper is that which now follows. It is well known that Weber's patient and thorough researches on the energy of assimilation led to two important results, among others: (I) that the quantity of starch formed by a certain area of leaf-surface in a certain time may be relatively very large ; and (2) that different plant; probably differ specifically as to the quantities of starch formed in their leaves.

Sachs proposes to apply his method to the solution of this question, i.e. how much starch is produced in, say, one square metre of leaf-surface by assimilation during, say, ten hours' bright sunlight? The great difficulties in Weber's researches were connected with the enormous labour necessary to measure the leaf-surface accurately.

Sachs resolved the matter in a manner which we may summarise thus:- He cut off portions of large leaves found to be empty of starch, measured them rapidly by laying them on pifces of board cut to the size of one square metre, and killed, dried, and weighed the measured portions very rapidly. Certain precautions as to the area of fibro-vascular bundles, the possibilities of absorbing hygroscopic moisture, \&c., may here be passed over. Sup osing these portions of the leaves to be estimated in the morning, a quantity of the same leaves of equal area gathered in the evening was then compared, and the increase in weight gives the quantity of starch formed in the interval. By weighing large areas, and frequently, and by payirg attention to the times and other cirsumstances, a large number of results were obtained, showing that the quantities given by Weber, for instance, are within the mark. Cf course these results are not absolute. Starch is tein $r$ changed into glucose, and passing away during the cay, and some must be burnt off in respiration; moreover a certain minute quantity of mineral ash should be allowed for. Of course, it is an assumption that equal areas of mesophyll of the same leaves contain approximately the same amount of substance: nevertheless, if a large number of experiments are made, the error is probably small.

Experiments were made to show both the quantities of starch which disappear during the night and the quanti- 
ties formed during the day. A few of the numbers may be given. In Helianthus, 9.64 grms. of starch disappeared in ten hours from one square metre of leafsurface.

In the same plant 9.14 grms. were formed in the same time by the same area of leaf-surface.

In another case Helianthus was used, but the leaves were removed from the stem to prevent the passage back of the starch from the mesophyll into the stems.

A square metre was found to produce starch at the rate of $\mathrm{I} \cdot 648$ grms. per hour.

By combining his experimental results and taking note of all the circumstances, Sachs concludes that twenty to twenty-five grms. of starch per day may be produced by one square metre of leaf-surface as an ordinary occurrence; and these numbers are not only not excessive, but experiments show that there are plants which produce much more than those investigated here.

Some remarkably interesting and important results follow from the consideration of these experimental data.

They explain why plants are so vigorous during warm nights following upon hot bright days. The more readily the products of assimilation (formed in large quantities during the day) can pass into the growing organs, the better these are nourished, and so forth.

Leaves used for fodder, \&c., must differ in nutritive value to a very great extent if their starchy contents vary so largely during the day and night: it thus becomes of primary importance whether such leaves are gathered in the morning or the evening, in cold or warm weather, \&c. The same applies to Tobacco and Tea, \&c. It must make a vast difference to the smoker whether his tobacco abounds in carbohydrates or is relatively richer in the alkaloids. It appears that tobacco is habitually cropped in the morning in some countries, a fact which suggests that experience has already shown that a difference in the quality exists ; it will be interesting to inquire further into these matters.

Sachs's results will also materially affect the physiological value of the analyses of leaves. Some of us know how great are the variations met with in analyses of the ash contents of leaves of the same plant. It is clear that, in addition to the age of the leaf, the soil, manure, \&c., it is important to know the amount of starch present. It cannot but happen that the mineral matters ebb and flow as well as the starch. The analyses of leaves will also be more valuable for the purposes of physiology if the numbers are stated, not in simple percentages, but in terms of one square metre of the leaf-surface.

The above brief summary of the results obtained by Prof. Sachs by no means does justice to the beauty of his methods, and the masterly way in which they were carried out: it must be admitted by all who understand the value and importance of this work that it is worthy of the great pioneer of vegetable physiology. Moreover, it suggests several matters which require further investigation, and would no doubt yield valuable results to those fortunate enough to have a botanical garden at band.

Botanical Laboratory, Owens College partment. Our information is derived from this article and from others by M. Hospitalier.

The method previously adopted by Van Rysselberghe, to prevent induction from taking place between the telegraph wires and those running parallel to them used for telephone work, was briefly as follows:-The system of sending the dots and dashes of the code-usually done by depressing and raising a key which suddenly turns on the current and then suddenly turns it off--was modified so that the current should rise gradually and fall gradually in its strength by the introduction of suitable resistances. These were introduced into the circuit at the moment of

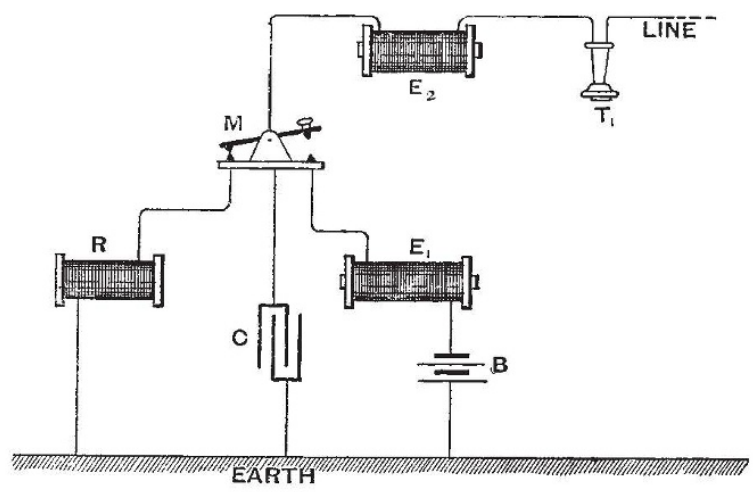

Fig. I

closing or opening by a simple automatic arrangement worked exactly as before by a key. The result of the gradual opening and gradual closing of the circuit was that the current attained its full strength gradually instead of suddenly, and died away also gradually. And as induction from one wire to another depends not on the strength of the current, but on the rate at which the strength changes, this very simple modification had the effect of suppressing induction. Later Van Rysselberghe changed these arrangements for the still simpler device of introducing permanently into the circuit either condensers or else electromagnets having a high coefficient

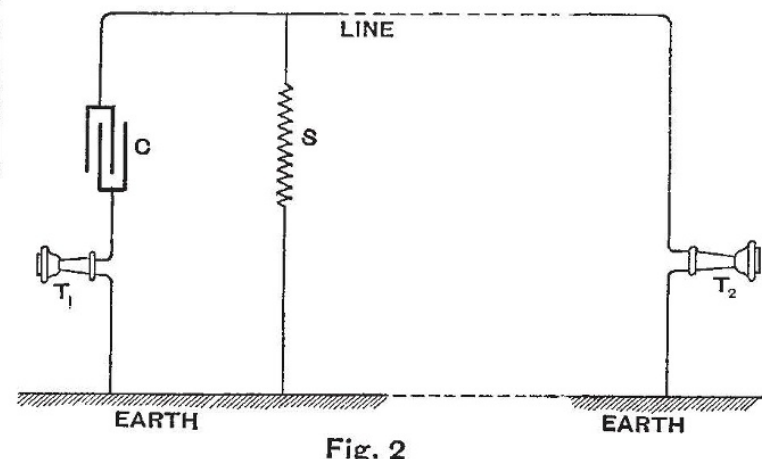

of self-induction. These, as is well known to all telegraphic engineers, retard the rise or fall of an electric current; they fulfil the conditions required for the working of Van Rysselberghe's method better than any other device.

Having got thus far in his devices for destroying induction from one line to another, Van Rysselberghe saw that, as an immediate consequence, it might be concluded that, if the telegraphic currents were thus modified and graduated so that they produced no induction in a neighbouring telephone line, they would produce no sound in the telephone if that instrument were itself joined up in the telegraph line. And such was found to be the case 